\title{
Novel genetic variations associated with salt sensitivity in the Korean population
}

\author{
Moo-Yong Rhee ${ }^{1,8}$, Soo Jin Yang ${ }^{2,8}$, Sang Woo $\mathrm{Oh}^{3}$, Yongsoon Park ${ }^{4}$, Cho-il Kim ${ }^{5}$, Hye-Kyung Park ${ }^{6}$, \\ Sung Woo Park ${ }^{7}$ and Cheol-Young Park ${ }^{7}$
}

Salt sensitivity is a risk factor for cardiovascular morbidity and mortality. To date, only a few genetic variations have been identified as being associated with salt sensitivity. This study aimed to estimate the prevalence of salt sensitivity in the Korean population and to identify genetic variants affecting its development. A total of 101 Korean participants consumed a low-salt diet for 7 days followed by a high-salt diet for 7 additional days. Salt sensitivity was determined by noting any significant elevation in the 24-h mean arterial blood pressure. To determine genetic variants affecting salt sensitivity, 36 single-nucleotide polymorphisms (SNPs) that were previously reported to be associated with hypertension were tested for any associations with salt sensitivity. Of the 101 subjects, $28(27.7 \%)$ were determined to have salt sensitivity. Out of the 36 SNPs tested, four were significantly associated with salt sensitivity after adjusting for confounding factors: rs2681472 in ATPase, $\mathrm{Ca}^{++}$transporting, plasma membrane 1 (ATP2B1), rs7961152 in branched chain aminotransferase 1 (BCAT1), rs16998073 in fibroblast growth factor 5 (FGF5) and rs2398162 in LOC100132798. For rs3754777 in serine threonine kinase 39 (STK39) and rs1937506, associations with salt sensitivity were observed before adjusting for confounding factors. Haplotype analysis revealed that the A-C haplotype of rs3754777-rs6749447 in STK39 was more frequent in the salt-sensitive group compared with the saltresistant group, and was associated with salt sensitivity. This study estimates the prevalence of salt sensitivity in the Korean population and demonstrates a novel association between salt sensitivity and the ATP2B1, BCAT1, FGF5, LOC100132798 and STK39 genetic variations.

Hypertension Research (2011) 34, 606-611; doi:10.1038/hr.2010.278; published online 13 January 2011

Keywords: blood pressure; salt sensitivity; single-nucleotide polymorphism

\section{INTRODUCTION}

Hypertension, a complex trait that is influenced by both genetic and environmental factors, is a serious public health burden that affects about one-third of adults worldwide, ${ }^{1}$ and is associated with an increased risk of cardiovascular diseases. Although it has been suggested that dietary salt intake is strongly linked to high blood pressure, ${ }^{2,3}$ studies of the effects of dietary sodium reduction on blood pressure often show that alterations in sodium intake lead to minimal reductions in blood pressure. ${ }^{4,5}$ This relationship is likely because of the part to the heterogeneity of blood pressure responses to alterations in dietary sodium intake. Salt sensitivity, defined as significant changes in blood pressure on the depletion or repletion of dietary salt, accounts for about $50 \%$ of cases of essential hypertension. ${ }^{6}$ Salt sensitivity has been associated with an increase in cardiovascular disease and the reduced survival of both normotensive and hypertensive individuals. ${ }^{7}$
The identification of common genetic variants affecting hypertension has been challenging because of its multifactorial etiology, complex pathophysiology and limited statistical power. ${ }^{8}$ Previous genome-wide association (GWA) studies, including the Wellcome Trust Case Control Consortium study and the Framingham Heart Study 100K Project, have suggested that several genetic variants may be associated with hypertension. However, none of these studies have achieved genome-wide significance $\left(P<5 \times 10^{-7}\right) .{ }^{9,10}$ Recently, obstacles hindering the identification of genetic variants have been overcome through the use of larger sample sizes and advances in genotype-calling algorithms and analytical methods. Thus, a greater number of genetic variants that are highly associated with hypertension $\left(P<5 \times 10^{-7}\right)$ have been found. ${ }^{11,12}$ Given that numerous genes are reported to be associated with hypertension and that the prevalence of salt sensitivity in hypertensive subjects is relatively high, multiple genes with variant alleles associated with hypertension are believed to be linked to salt sensitivity.

\footnotetext{
${ }^{1}$ Cardiovascular Center, Dongguk University Ilsan Hospital, Goyang, Gyeonggi, Korea; ${ }^{2}$ Diabetes Research Institute, Sungkyunkwan University School of Medicine, Kangbuk Samsung Hospital, Seoul, Korea; ${ }^{3}$ Center for Obesity, Nutrition and Metabolism, Department of Family Medicine, Dongguk University Ilsan Hospital, Goyang, Gyeonggi, Korea; ${ }^{4}$ Department of Food and Nutrition, Hanyang University, Seoul, Korea; ${ }^{5}$ Center for Nutrition Policy and Promotion, Korea Health Industry Development Institute, Seoul, Korea; ${ }^{6}$ Nutrition Policy Division, Nutrition Policy Office, Food Safety Bureau, Seoul, Korea and ${ }^{7}$ Department of Endocrinology and Metabolism, Sungkyunkwan University School of Medicine, Kangbuk Samsung Hospital, Seoul, Korea

8These authors contributed equally to this work.

Correspondence: Dr C-Y Park, Department of Endocrinology and Metabolism, Sungkyunkwan University School of Medicine, Kangbuk Samsung Hospital, Seoul 110-746, Korea. E-mail: cydoctor@chol.com

Received 5 July 2010; revised 5 November 2010; accepted 28 November 2010; published online 13 January 2011
} 
The goal of this study was to estimate the prevalence of salt sensitivity in the Korean population and to identify genetic variants affecting the development of salt sensitivity by analyzing 36 single nucleotide polymorphisms (SNPs) previously reported to be associated with hypertension.

\section{METHODS}

\section{Subjects}

The study subjects consisted of 101 volunteers between the ages of 18 and 65 years (mean age $46 \pm 17$ years); 51 of the participants were men $(50 \%)$. We excluded volunteers with stage 2 hypertension (blood pressure $\geqslant 160 /$ $100 \mathrm{~mm} \mathrm{Hg}$ ), secondary hypertension, angina pectoris, diabetes mellitus, chronic kidney disease (estimated glomerular filtration rate by the Modification of Diet in Renal Disease equation $<60 \mathrm{ml} \mathrm{min}^{-1}$ ) and congestive cardiac failure, volunteers who had experienced a myocardial infarction or a stroke, and volunteers who were taking diuretics or any medications that affect blood pressure and could not be safely discontinued. Volunteers who were pregnant, lactating or who were engaged in heavy alcohol consumption were also excluded. The Dongguk University institutional review board approved the study protocol, and written informed consent was obtained from all participants.

\section{Determination of salt sensitivity}

After the eligibility of each subject was confirmed, all participants were asked to discontinue any medications, including antihypertensives that affect blood pressure and urinary electrolyte excretion, for at least 2 weeks before to the study. All eligible participants were hospitalized and administered a low-salt $\operatorname{diet}(100 \mathrm{mmol} \mathrm{NaCl}$ per day) for 7 days followed by a high-salt diet $(300 \mathrm{mmol}$ $\mathrm{NaCl}$ per day) for 7 additional days. All three meals consumed by participants each day were cooked by trained dieticians based on the hospital's standard dietary plan. Dietary compliance was verified by two trained dieticians. Participants who could not consume $>90 \%$ of meals were dropped from the study; dietary compliance was $99.8 \%$. In addition, all participants were hospitalized, their daily activity was monitored and their access to other food in addition to study meals was prohibited. The $24-\mathrm{h}$ ambulatory blood pressure for each volunteer was measured on the last day of each diet period using an automated, non-invasive oscillometric device (P6 Pressurometer; Del Mar Reynolds, Irvine, CA, USA) attached to the left upper arm. Salt sensitivity was defined as an increase of $>4 \mathrm{~mm} \mathrm{Hg}(P<0.05)$ in the mean arterial pressure (MAP) in response to the high-salt diet. The MAP was calculated with the following equation: $\mathrm{MAP}=(2$ diastolic blood pressure + systolic blood pressure)/3. Blood samples were obtained before the initial 2-week test period, and at the conclusion of the low-salt and high-salt diet periods. All blood samples were taken after an overnight fast. Glucose, triglyceride, total cholesterol, high-density lipoprotein cholesterol, aspartate aminotransferase and alanine aminotransferase were measured in each blood sample. Low-density lipoprotein cholesterol levels were calculated according to the following equation: low-density lipoprotein cholesterol=total cholesterol-high-density lipoprotein cholesterol-(triglyceride/5).

\section{Selection of SNPs and genotyping}

Candidate SNPs were selected from recent GWA and large candidate gene association studies. ${ }^{911-17}$ After excluding SNPs with a minor allele frequency $<0.01$ or a Hardy-Weinberg equilibrium $P$-value $<0.001$, a total of 36 SNPs were analyzed for an association with salt sensitivity. Genotyping was accomplished via a single base primer extension assay using an ABI PRISM SNaPshot Multiplex kit (Applied Biosystems, Foster City, CA, USA) according to the manufacturer's instructions. Briefly, the genomic DNA flanking each SNP was amplified by PCR with forward and reverse primer pairs and standard PCR reagents in a $10 \mu \mathrm{l}$ reaction volume containing $10 \mathrm{ng}$ of genomic DNA, $0.5 \mathrm{pM}$ of each oligonucleotide primer, $1 \mu \mathrm{l}$ of $10 \times$ PCR buffer, $250 \mu \mathrm{M}$ deoxynucleotide triphosphate $(2.5 \mathrm{~mm}$ each) and $0.25 \mathrm{U}$ i-StarTaq DNA Polymerase

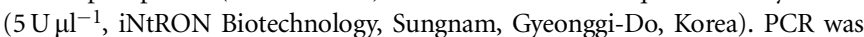
performed as follows: $10 \mathrm{~min}$ at $95^{\circ} \mathrm{C}$ for 1 cycle, followed by 35 cycles at $95^{\circ} \mathrm{C}$ for $30 \mathrm{~s}, T_{\mathrm{m}}{ }^{\circ} \mathrm{C}$ for $1 \mathrm{~min}, 72{ }^{\circ} \mathrm{C}$ for $1 \mathrm{~min}$ and 1 cycle at $72{ }^{\circ} \mathrm{C}$ for $10 \mathrm{~min}$. After amplification, the PCR products were treated with $1 \mathrm{U}$ each of shrimp alkaline phosphatase (SAP; USB Corporation, Cleveland, OH, USA) and exonuclease I (USB Corporation) at $37^{\circ} \mathrm{C}$ for $75 \mathrm{~min}$ and $72{ }^{\circ} \mathrm{C}$ for $15 \mathrm{~min}$ to purify the amplified products. For the primer extension reaction, $1 \mu \mathrm{l}$ of the purified amplification products was added to a SNaPshot Multiplex Ready reaction mixture (Applied Biosystems) containing $0.15 \mathrm{pmol}$ of genotyping primer. The primer extension reaction was performed for 25 cycles at $96^{\circ} \mathrm{C}$ for $10 \mathrm{~s}, 50^{\circ} \mathrm{C}$ for $5 \mathrm{~s}$ and $60^{\circ} \mathrm{C}$ for $30 \mathrm{~s}$. The reaction products were treated with $1 \mathrm{U}$ of SAP at $37^{\circ} \mathrm{C}$ for $1 \mathrm{~h}$ and $72^{\circ} \mathrm{C}$ for $15 \mathrm{~min}$ to remove excess fluorescent dye terminators. Aliquots of $1 \mu \mathrm{l}$ of the final reaction sample containing the extension products were added to $9 \mu \mathrm{l}$ of Hi-Di formamide (Applied Biosystems). The mixture was incubated at $95^{\circ} \mathrm{C}$ for $5 \mathrm{~min}$, held in ice for $5 \mathrm{~min}$ and analyzed by electrophoresis using an ABI Prism $3730 \times 1$ DNA analyzer. Genemapper software (version 4.0; Applied Biosystems) was used for the analysis.

\section{Statistical analysis}

PASW Statistics 17 software (SPSS, Chicago, IL, USA) was used to perform all statistical analyses. Data are expressed as the mean \pm s.d. for normally distributed variables, and as a median and interquartile range for variables that are not normally distributed. The significance of differences between the groups was evaluated using a Student's $t$-test, one-way analysis of variance, MannWhitney test or Kruskal-Wallis test, depending on whether the data were normally distributed. The differences in frequencies between groups were tested for statistical significance with $\chi^{2}$-tests. The association between genotypes and the incidence of salt sensitivity was analyzed by multivariate logistic regression analysis after adjusting for age and sex. The association between each SNP and salt sensitivity was examined through the use of four different models (minor allele dominant, minor allele recessive, minor allele additive and minor allele frequency models). For each SNP, the model with the highest likelihood of developing salt sensitivity in the logistic regression model was selected. Taking into account the fact that 36 SNPs were tested in parallel, a Bonferroni's correction was performed for the associations between SNPs and salt sensitivity to correct for multiple testing. Haplotypes were generated using PHASE v2.1 (available at http://www.stat.washington.edu/stephens/phase/ download.html), ${ }^{18}$ and haplotype statistics were determined using Haploview v4.1. ${ }^{19}$ A multifactor dimensionality reduction analysis was done with multifactor dimensionality reduction software package (available at http://www. multifactordimensionalityreduction.org) to detect gene-gene interactions. Values of $P<0.05$ were considered to be statistically significant.

\section{RESULTS}

\section{Basic characteristics}

A total of 28 participants $(27.7 \%)$ were determined to have salt sensitivity. The baseline characteristics of salt-sensitive and salt-resistant subjects are summarized in Table 1. Sex distribution, body weight, body mass index and metabolic parameters (fasting glucose, triglyceride, total cholesterol, low-density lipoprotein cholesterol, high-density lipoprotein cholesterol, aspartate aminotransferase and alanine aminotransferase) did not differ between the groups. The mean age of the participants with salt sensitivity was significantly higher than the mean age of those who remained salt resistant. This result is consistent with previous findings in normotensive and hypertensive subjects. ${ }^{2}$ The overall height was also significantly different between groups.

\section{SNPs significantly associated with the development of salt sensitivity}

All 36 SNPs tested were in Hardy-Weinberg equilibrium $(P>0.05)$; four were significantly associated with salt sensitivity in a multivariate logistic regression analysis adjusted for confounding factors: rs2681472 in ATPase, $\mathrm{Ca}^{++}$transporting, plasma membrane 1 (ATP2B1), rs7961152 in branched chain aminotransferase 1 (BCAT1), rs16998073 in fibroblast growth factor 5 (FGF5) and rs2398162 in LOC100132798 (see Table 2). The minor allele dominant model showed that rs7961152 in BCAT and rs2398162 in LOC100132798 had the highest likelihood of developing salt sensitivity, whereas the minor allele recessive model showed that 
Table 1 Subject characteristics

\begin{tabular}{|c|c|c|c|}
\hline & $\begin{array}{l}\text { Salt resistant } \\
\quad(n=73)\end{array}$ & $\begin{array}{l}\text { Salt sensitive } \\
\qquad(n=28)\end{array}$ & P-value \\
\hline Age (years) & $43 \pm 17$ & $54 \pm 13$ & 0.001 \\
\hline Sex (male/female) & $40 / 33$ & $11 / 17$ & 0.163 \\
\hline Height (cm) & $165 \pm 9$ & $159 \pm 8$ & 0.005 \\
\hline Weight (kg) & $66.3 \pm 13.1$ & $64.5 \pm 13.1$ & 0.534 \\
\hline BMI $\left(\mathrm{kg} \mathrm{m}^{-2}\right)$ & $24.1 \pm 3.6$ & $25.3 \pm 4.0$ & 0.181 \\
\hline Fasting blood glucose $\left(\mathrm{mmol} \mathrm{I}^{-1}\right)$ & $5.2 \pm 0.6$ & $5.3 \pm 0.5$ & 0.162 \\
\hline Triglyceride $\left(\mathrm{mmol} \mathrm{I}^{-1}\right)$ & $1.6 \pm 0.7$ & $1.8 \pm 0.8$ & 0.275 \\
\hline Total cholesterol $\left(\mathrm{mmoll}^{-1}\right)$ & $4.9 \pm 1.0$ & $5.1 \pm 0.9$ & 0.439 \\
\hline LDL cholesterol (mmol I-1) & $3.0 \pm 0.9$ & $3.1 \pm 0.8$ & 0.617 \\
\hline HDL cholesterol $\left(\mathrm{mmol}^{-1}\right)$ & $1.2 \pm 0.3$ & $1.2 \pm 0.4$ & 0.934 \\
\hline AST $\left(U I^{-1}\right)$ & $19.3 \pm 7.3$ & $20.8 \pm 8.7$ & 0.372 \\
\hline $\operatorname{ALT}\left(U I^{-1}\right)$ & $19.5 \pm 12.9$ & $21.0 \pm 14.5$ & 0.609 \\
\hline
\end{tabular}

Abbreviations: ALT, alanine aminotransferase; AST, aspartate aminotransferase; BMI, body mass index; HDL, high-density lipoprotein; LDL, low-density lipoprotein.

Data are expressed as mean \pm s.d.

rs2681472 in ATP2B1 had the highest likelihood of developing salt sensitivity. The SNP rs16998073 in FGF5 exhibited the highest likelihood of developing salt sensitivity in the minor allele additive model. The association with salt sensitivity did not remain significant at a conservative Bonferroni-corrected level. For rs3754777 in serine threonine kinase 39 (STK39) and rs1937506, associations with salt sensitivity $(P=0.040$ and 0.006 , respectively) were observed before adjusting for confounding factors. However, the association was not significant after adjusting for age and sex. Details regarding the associations between other SNPs and salt sensitivity are shown in Table 2.

In addition, an association analysis was performed to identify SNPs associated with changes in MAP between low-salt and high-salt diets. The SNPs rs2398162 in LOC100132798 and rs1937506 were significantly associated with changes in MAP between low-salt and high-salt diets (Table 3). These SNPs were the ones significantly associated with salt sensitivity before adjusting for confounding factors, and the association for rs2398162 remained significant even after adjusting for confounding factors.

The genotype frequencies of the four significant SNPs are shown in Table 4. Although there were no significant changes with respect to the genotype in the 24-h systolic blood pressure when going from a lowto a high-salt diet, salt-induced changes measured by the 24 -h diastolic blood pressure and 24-h MAP were significantly higher for GT and TT in rs7961152 (BCAT), TT in rs16998073 (FGF5) and GA in rs2398162 (LOC100132798; see Table 4). This finding suggests that these alleles are regulatory alleles that control blood pressure.

\section{Association of STK39 haplotype with salt sensitivity}

Haplotype association with salt sensitivity was tested on four haplotype groups generated by PHASE v2.1: (1) rs1378942 in c-src tyrosine kinase-rs6495122, (2) rs4532-rs5326-rs265981 in type 1 dopamine receptor, (3) rs1024323-rs1801058-rs2960306 in G protein-coupled receptor kinase type 4 and (4) rs3754777-rs6749447 in STK39. Among the tested haplotype groups, the A-C haplotype of rs3754777-rs6749447 in STK39 occurred more frequently than other haplotypes in the salt-sensitive group compared with the salt-resistant group (Table 5), and showed a significant association with salt sensitivity (odds ratio $=5.3, P=0.034$ ). In addition, the multifactor dimensionality reduction method was used for a gene-gene interaction analysis; ${ }^{20}$ however, no significant gene-gene interactions were identified for salt sensitivity.

\section{DISCUSSION}

Previous studies suggest that salt sensitivity is a risk factor for developing hypertension and other cardiovascular diseases, and that genetic factors contribute to salt sensitivity susceptibility. ${ }^{714,21-22}$ Given both the high prevalence of salt sensitivity (about 50\%) in cases of essential hypertension and the emergence of publications showing the influence of SNPs on the development of hypertension, it has been hypothesized that many hypertension-associated SNPs may influence the development of salt sensitivity. In this work, four SNPs and one haplotype were found to be associated with the development of salt sensitivity: rs2681472 in ATP2B1, rs7961152 in BCAT1, rs16998073 in FGF5, rs2398162 in LOC100132798 and the A-C haplotype of rs3754777-rs6749447 in STK39.

The SNP rs2681472 is located in ATP2B1, a plasma membrane calcium ATPase that is associated with the homeostasis of cellular calcium ion levels and the control of vascular reactivity and blood pressure. ${ }^{23}$ A GWA study of blood pressure and hypertension in the Cohorts for Heart and Aging Research in Genome Epidemiology study and the Global Blood Pressure Genetics Consortium demonstrated a strong association of rs2681472 with blood pressure and the development of hypertension. ${ }^{11}$ The functional importance of genetic variations in ATP2B1 with regard to the regulation of blood pressure was highlighted by the findings of several other GWA studies that identified additional significant SNPs in or near ATP2B1. These SNPs included rs2681492, rs11105354 and rs17249754. ${ }^{11,13,24,25}$ Regardless of the involvement of these SNPs in hypertension, their association with salt sensitivity has not yet been documented. In this study, a significant association between $\mathrm{rs} 2681472$ in ATP2B1 and the development of salt sensitivity was demonstrated.

The strongest association between a SNP and salt sensitivity was observed for rs7961152, which is located in cytosolic BCAT1, an enzyme that catalyzes the reversible transamination of branched-chain $\alpha$-keto acids to branched-chain L-amino acids. BCAT1 is known to have a role in cell growth and apoptosis. ${ }^{26,27}$ Although the functional involvement of rs7961152 in the development of salt sensitivity and hypertension has not yet been reported, previous studies have shown the association of rs7961152 with systolic and diastolic blood pressure, ${ }^{28}$ as well as with hypertension. ${ }^{9}$

FGF5 is a member of the FGF family that mediates a variety of biological processes, including embryonic development, cell growth, morphogenesis, tissue repair, and tumor growth and invasion. ${ }^{29,30}$ A recent GWA study that focused on blood pressure revealed eight blood pressure-associated genetic variants, including rs16998073 in FGF5, suggesting a possible role in blood pressure control. ${ }^{12}$ Regarding rs2398162 in LOC100132798, an association with hypertension has been suggested in a Wellcome Trust Case Control Consortium study. ${ }^{9}$ However, a replication study in a Korean sample failed to confirm this association. ${ }^{28}$ In this work, the finding that two SNPs (rs16998073 and rs2398162) were significantly associated with salt sensitivity suggested that further studies are needed to investigate functions related to blood pressure control with regard to the two genetic variations.

In addition to the above results, rs3754777 in STK39 exhibited a possible association with salt sensitivity only when analyzed before the adjustment of confounding factors. Moreover, haplotype analysis revealed a significant association between the STK39 haplotype and salt sensitivity. The strong association between salt sensitivity and two SNPs (rs3754777 and rs6749447) in the STK39 gene, which encodes the Ste29-related proline-alanine-rich kinase protein, was reported in a GWA study in the Old Order Amish population and was confirmed in a separate meta-analysis. ${ }^{16}$ In the aforementioned paper, the authors suggested that STK39 may regulate blood pressure 
Table 2 Multivariate logistic regression analysis of SNPs associated with salt sensitivity

\begin{tabular}{|c|c|c|c|c|c|c|c|}
\hline SNP & Gene & Alleles 1/2 & $M A F$ & Odds ratio & $95 \% \mathrm{Cl}$ & P-value & Model \\
\hline rs12946454 & $A C B D 4$ & $\mathrm{~T} / \mathrm{A}$ & 0.187 & 0.7 & $0.3-1.6$ & 0.389 & $\mathrm{~T} / \mathrm{A}$ \\
\hline rs4341 & $A C E$ & $C / G$ & 0.376 & 0.7 & $0.2-2.7$ & 0.550 & $\mathrm{CC}+\mathrm{CG} / \mathrm{GG}$ \\
\hline rs4961 & $A D D 1$ & $\mathrm{~T} / \mathrm{G}$ & 0.371 & 1.4 & $0.5-3.6$ & 0.530 & $\mathrm{TT} / \mathrm{TG}+\mathrm{GG}$ \\
\hline rs699 & $A G T$ & $\mathrm{C} / \mathrm{T}$ & 0.168 & 1.8 & $0.7-4.8$ & 0.250 & $\mathrm{CC} / \mathrm{CT} / \mathrm{TT}$ \\
\hline rs5186 & AGTR1 & $\mathrm{A} / \mathrm{C}$ & 0.021 & 2.7 & $0.3-22.4$ & 0.360 & $\mathrm{AA} / \mathrm{AC} / \mathrm{CC}$ \\
\hline rs2681472 & ATP2B1 & $\mathrm{T} / \mathrm{C}$ & 0.410 & 3.8 & $1.1-13.7$ & 0.040 & $(\mathrm{TT}+\mathrm{TC}) / \mathrm{CC}$ \\
\hline rs6594013 & ATP2B4 & $\mathrm{A} / \mathrm{T}$ & 0.369 & 1.4 & $0.4-5.3$ & 0.650 & $\mathrm{AA}+\mathrm{AT} / \mathrm{TT}$ \\
\hline rs7961152 & BCAT1 & $\mathrm{G} / \mathrm{T}$ & 0.105 & 4.9 & $1.5-15.5$ & 0.007 & $\mathrm{GG} /(\mathrm{GT}+\mathrm{TT})$ \\
\hline rs1530440 & C10orf107 & $\mathrm{C} / \mathrm{T}$ & 0.175 & 0.7 & $0.3-1.8$ & 0.495 & $\mathrm{C} / \mathrm{T}$ \\
\hline rs11014166 & CACNB2 & $A / T$ & 0.116 & 1.0 & $0.3-3.2$ & 0.946 & AA/AT/TT \\
\hline rs1378942 & CSK & $\mathrm{C} / \mathrm{A}$ & 0.150 & 0.6 & $0.2-1.7$ & 0.343 & $\mathrm{CC} / \mathrm{CA}+\mathrm{AA}$ \\
\hline rs1799998 & CYP11B2 & $\mathrm{T} / \mathrm{C}$ & 0.340 & 1.1 & $0.5-2.1$ & 0.860 & $\mathrm{~T} / \mathrm{C}$ \\
\hline rs1004467 & CYP17A1 & $\mathrm{T} / \mathrm{C}$ & 0.305 & 0.7 & $0.3-1.8$ & 0.502 & $\mathrm{TT} / \mathrm{TC}+\mathrm{CC}$ \\
\hline rs4532 & DRD1 & $A / G$ & 0.119 & 1.3 & $0.4-3.7$ & 0.680 & $\mathrm{AA} / \mathrm{AG}+\mathrm{GG}$ \\
\hline rs5326 & $D R D 1$ & $\mathrm{G} / \mathrm{A}$ & 0.273 & 0.7 & $0.3-1.7$ & 0.404 & $\mathrm{GG} / \mathrm{GA}+\mathrm{AA}$ \\
\hline rs265981 & $D R D 1$ & $\mathrm{C} / \mathrm{T}$ & 0.110 & 1.5 & $0.5-4.4$ & 0.508 & $\mathrm{CC} / \mathrm{CT}+\mathrm{TT}$ \\
\hline rs16998073 & FGF5 & $\mathrm{A} / \mathrm{T}$ & 0.405 & 2.1 & $1.0-4.2$ & 0.042 & $\mathrm{AA} / \mathrm{AT} / \mathrm{TT}$ \\
\hline rs5443 & GNB3 & $\mathrm{T} / \mathrm{C}$ & 0.495 & 1.5 & $0.5-4.3$ & 0.500 & $\mathrm{TT} / \mathrm{TC}+\mathrm{CC}$ \\
\hline rs1024323 & GRK4 & $\mathrm{C} / \mathrm{T}$ & 0.18 & 0.6 & $0.3-1.5$ & 0.300 & $\mathrm{C} / \mathrm{T}$ \\
\hline rs1801058 & GRK4 & $\mathrm{T} / \mathrm{C}$ & 0.431 & 1.4 & $0.7-2.8$ & 0.280 & $\mathrm{~T} / \mathrm{C}$ \\
\hline rs2960306 & GRK4 & $\mathrm{G} / \mathrm{T}$ & 0.115 & 0.8 & $0.3-2.2$ & 0.660 & $\mathrm{G} / \mathrm{T}$ \\
\hline rs2398162 & LOC100132798 & $G / A$ & 0.380 & 3.5 & $1.2-10.4$ & 0.023 & $\mathrm{GG} /(\mathrm{GA}+\mathrm{AA})$ \\
\hline rs17367504 & MTHFR & $\mathrm{T} / \mathrm{C}$ & 0.091 & 1.5 & $0.5-4.7$ & 0.519 & $\mathrm{TT} / \mathrm{TC} / \mathrm{CC}$ \\
\hline rs11110912 & MYBPC1 & $C / G$ & 0.081 & 2.4 & $0.5-10.8$ & 0.273 & $\mathrm{CC} / \mathrm{CG} / \mathrm{GG}$ \\
\hline rs4149601 & NEDD4L & $\mathrm{G} / \mathrm{A}$ & 0.082 & 0.4 & $0.1-1.5$ & 0.174 & $\mathrm{G} / \mathrm{A}$ \\
\hline rs11191848 & $O B F C 1$ & $A / G$ & 0.360 & 0.5 & $0.2-1.0$ & 0.054 & $A / G$ \\
\hline rs381815 & PLEKHA7 & $G / A$ & 0.190 & 1.9 & $0.7-5.0$ & 0.174 & $\mathrm{GG} / \mathrm{GA}+\mathrm{AA}$ \\
\hline rs3754777 & STK39 & $\mathrm{G} / \mathrm{A}$ & 0.225 & 5.0 & $0.5-51.2$ & 0.178 & $\mathrm{GG}+\mathrm{GA} / \mathrm{AA}$ \\
\hline rs6749447 & STK39 & $\mathrm{C} / \mathrm{A}$ & 0.310 & 0.9 & $0.5-1.9$ & 0.830 & $\mathrm{C} / \mathrm{A}$ \\
\hline rs16948048 & ZNF652 & $\mathrm{T} / \mathrm{C}$ & 0.205 & 3.3 & $0.5-24.1$ & 0.235 & $\mathrm{TT}+\mathrm{TC} / \mathrm{CC}$ \\
\hline rs1937506 & & $\mathrm{G} / \mathrm{A}$ & 0.130 & 1.9 & $0.8-4.8$ & 0.153 & $\mathrm{G} / \mathrm{A}$ \\
\hline rs2384550 & & $\mathrm{G} / \mathrm{A}$ & 0.105 & 2.2 & $0.8-6.3$ & 0.152 & $\mathrm{GG} / \mathrm{GA} / \mathrm{AA}$ \\
\hline rs2820037 & & $\mathrm{A} / \mathrm{T}$ & 0.061 & 0.6 & $0.2-2.4$ & 0.483 & $\mathrm{~A} / \mathrm{T}$ \\
\hline rs6495122 & & $\mathrm{A} / \mathrm{C}$ & 0.155 & 0.5 & $0.2-1.4$ & 0.177 & $\mathrm{AA} / \mathrm{AC} / \mathrm{CC}$ \\
\hline rs6997709 & & $\mathrm{G} / \mathrm{T}$ & 0.095 & 0.3 & $0.1-1.5$ & 0.136 & $\mathrm{GG} / \mathrm{GT}+\mathrm{TT}$ \\
\hline rs9815354 & & $G / A$ & 0.210 & 0.7 & $0.1-7.4$ & 0.752 & $\mathrm{GG}+\mathrm{GA} / \mathrm{AA}$ \\
\hline
\end{tabular}

Abbreviations: ACBD4, acyl-co-enzyme A-binding domain containing 4; $A C E$, angiotensin-converting enzyme; ADD1, adducin 1 ( $\alpha$ ); AGT, angiotensinogen; AGTR1, angiotensin II type 1 receptor; ATP2B1, ATPase, $\mathrm{Ca}^{++}$transporting, plasma membrane 1; ATP2B4, ATPase, Ca++ transporting, plasma membrane 4; BCAT1, branched chain aminotransferase 1; C10orf107, chromosome 10 open reading frame 107; CACNB2, calcium channel, voltage-dependent, $\beta 2$ subunit; $C l$, confidence interval; CSK, c-src tyrosine kinase; CYP11B2, cytochrome P450, family 11 , subfamily $\mathrm{B}$, polypeptide 2; CYP17A1, cytochrome P450, family 17, subfamily A, polypeptide 1; DRD 1, type 1 dopamine receptor; FGF5, fibroblast growth factor 5; GNB3, G-protein $\beta 3$ subunit; GRK4, G polypeptide 2; CYP17A1, cytochrome P450, family 17, subfamily A, polypeptide 1; DRD1, type 1 dopamine receptor; FGF5, fibroblast growth factor 5 ; GNB3, G-protein $\beta 3$ subunit; GRK4, G
protein-coupled receptor kinase type 4; MAF, minor allele frequency; MTHFR, 5,10-methylenetetrahydrofolate reductase (nicotinamide adenine dinucleotide phosphate); MYBPC1, myosin-binding protein C, slow type; NEDD4L, neural precursor cell expressed, developmentally down-regulated 4-like; OBFC1, oligonucleotide/oligosaccharide-binding fold containing 1; PLEKHA7, pleckstrin homology domain containing, family A member 7; SNP, single-nucleotide polymorphism; STK39, serine threonine kinase 39; ZNF652, zinc-finger protein 652.

Multivariate logistic regression analysis was performed with adjustments for age and sex.

Table 3 Association analysis between SNPs and changes in mean arterial pressure from low-salt diet to high-salt diet

\begin{tabular}{lllllll}
\hline \multirow{2}{*}{ SNP } & Gene & GG & $G A$ & $A A$ & recessive & dominant \\
\hline rs2398162 & LOC100132798 & $0.3 \pm 4.0$ & $2.4 \pm 4.2$ & $1.3 \pm 5.0$ & 0.865 & 0.029 \\
rs1937506 & $1.4 \pm 4.4$ & $1.0 \pm 3.3$ & $7.5 \pm 3.5$ & 0.014 & 0.725 \\
\hline
\end{tabular}

Abbreviation: SNP, single-nucleotide polymorphism.

Data are expressed as mean \pm s.d.

by increasing its expression and altering renal sodium excretion through its interaction with WNK kinase and cation-chloride cotransporters. The SNP rs1937506 was significantly associated with salt sensitivity and changes in MAP between low-salt and high-salt diets before adjusting for confounding factors. The SNP rs1937506 is not linked to any gene and, with the exception of the Wellcome Trust Case
Control Consortium study, ${ }^{9}$ no research explaining its function or association has been published.

Previous association studies have demonstrated that individuals with genetic variants in adducin $1 \alpha$, angiotensinogen, CYP11B2 (cytochrome P450, family 11, subfamily B, polypeptide 2), G-protein â3 subunit, G protein-coupled receptor kinase type 4 and neural precursor cell expressed developmentally downregulated 4-like are more susceptible to developing salt sensitivity. ${ }^{14,15,21,22,31,32}$ Among these genetic variants, there is a growing body of evidence that Gly460Trp polymorphism (rs4961) in adducin $1 \alpha$, a heterodimeric cytoskeleton protein that is involved in cell signal transduction, the regulation of actin cytoskeleton and ion transport across the cell membrane, is associated with hypertension and salt sensitivity through the renal sodium retaining effect of the Trp allele. ${ }^{22,33}$ However, in this paper, no significant association was observed between salt sensitivity and genetic variants in adducin $1 \alpha$, angiotensinogen, 
Table 4 Salt-induced blood pressure changes in different genotype carriers

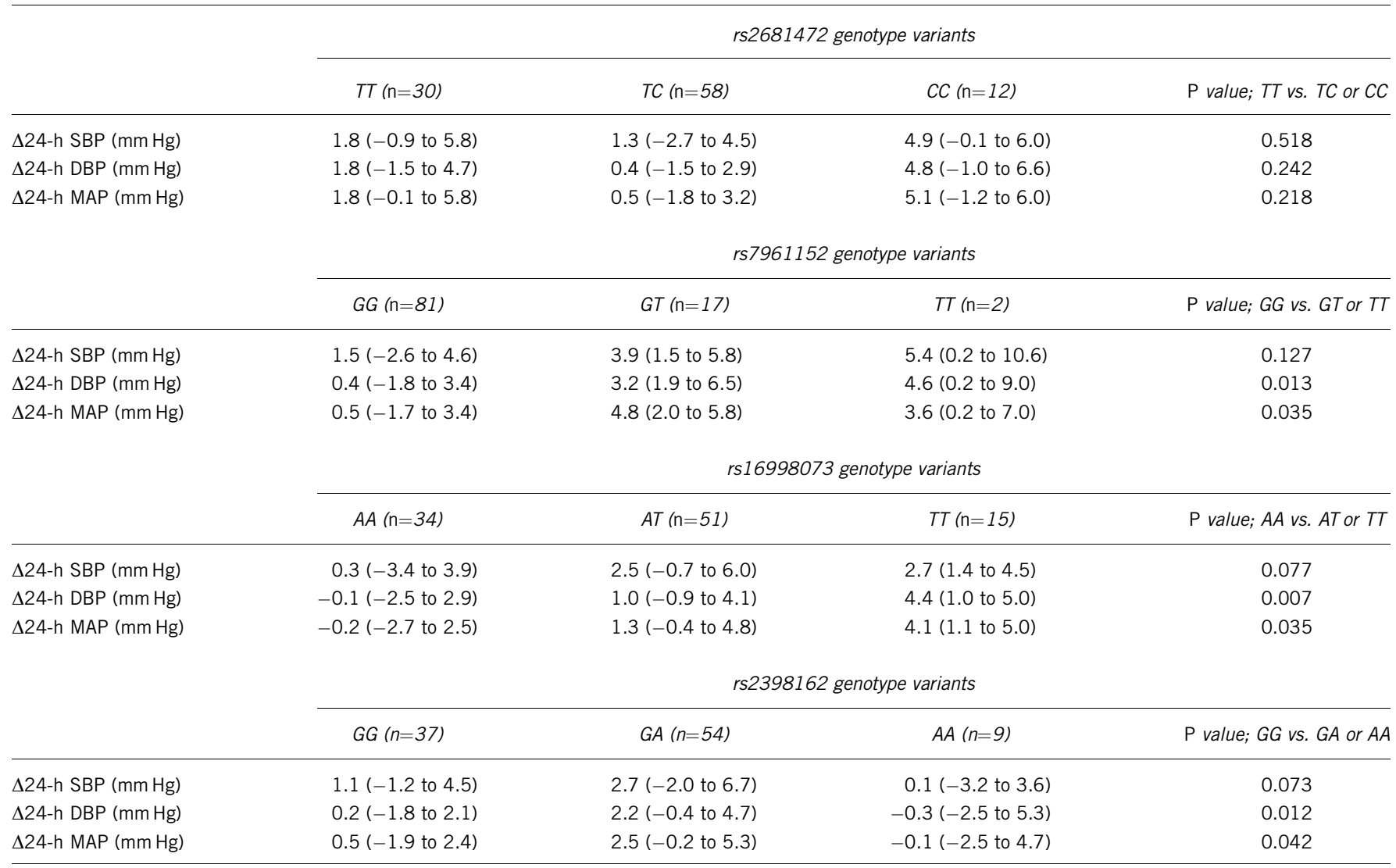

Abbreviations: $\Delta$ 24-h DBP, $\Delta 24$-h diastolic blood pressure; $\Delta 24$-h MAP, $\Delta 24$-h mean arterial blood pressure; $\Delta 24-\mathrm{h}$ SBP, $\Delta 24-\mathrm{h}$ systolic blood pressure. Data are expressed as median (interquartile range). Blood pressure change in low- vs. high-salt intake.

Table 5 STK39 rs3754777-rs6749447 haplotype frequencies in the study population

\begin{tabular}{lccc}
\hline Frequency & & \\
Haplotype & Salt resistant $(\mathrm{n}=73)$ & Salt sensitive $(\mathrm{n}=28)$ & P-value \\
\hline G-C & 0.465 & 0.464 & 0.365 \\
G-A & 0.326 & 0.268 & 0.422 \\
A-C & 0.208 & 0.268 & 0.039 \\
A-A & 0 & 0 & \\
\hline
\end{tabular}

Abbreviation: STK39, serine threonine kinase 39.

CYP11B2, G-protein $\beta 3$ subunit, G protein-coupled receptor kinase type 4 and neural precursor cell expressed developmentally downregulated 4-like. Such a discrepancy may be because of the differences in sample origin, methods of testing for salt sensitivity and the complexity and heterogeneity of salt sensitivity in relation to blood pressure.

To the best of our knowledge, this study is the first report regarding the details of salt sensitivity, its prevalence and related SNPs in a Korean sample. Although inconsistencies exist between previous reports and our findings, we demonstrated a novel association between salt sensitivity and genetic variations in ATP2B1, BCAT1, FGF5, LOC100132798 and STK39. Because the sample size of this cohort is relatively small and because certain aspects of hypertension were not considered, a more comprehensive study with a larger sample size and the consideration of prevalence, age of onset, severity and the complications of hypertension are required to replicate the associations detailed in this work. Furthermore, future research aimed at defining the functional role of each genetic variant identified in this paper on the risk of salt sensitivity will need to be performed. The accumulation of such evidence will allow for the use of diagnostic SNP screening tests for early detection of salt sensitivity and facilitate interventions to prevent the development of salt sensitive hypertension.

\section{CONFLICT OF INTEREST}

The authors declare no conflicts of interest.

\section{ACKNOWLEDGEMENTS}

This research was supported by a grant (08082KFDA999) from the Korea Food and Drug Administration in 2009.

1 Kearney PM, Whelton M, Reynolds K, Muntner P, Whelton PK, He J. Global burden of hypertension: analysis of worldwide data. Lancet 2005; 365: 217-223.

2 De Wardener HE, MacGregor GA. Sodium and blood pressure. Curr Opin Cardiol 2002; 17: 360-367.

3 Meneton P, Jeunemaitre X, de Wardener HE, MacGregor GA. Links between dietary salt intake, renal salt handling, blood pressure, and cardiovascular diseases. Physiol Rev 2005; 85: 679-715.

4 Hooper L, Bartlett C, Davey Smith G, Ebrahim S. Systematic review of long term effects of advice to reduce dietary salt in adults. BMJ 2002; 325: 628 .

5 Midgley JP, Matthew AG, Greenwood CM, Logan AG. Effect of reduced dietary sodium on blood pressure: a meta-analysis of randomized controlled trials. JAMA 1996; 275 : 1590-1597. 
6 Weinberger MH. Salt sensitivity of blood pressure in humans. Hypertension 1996; 27 (3 Part 2): 481-490.

7 Franco V, Oparil S. Salt sensitivity a determinant of blood pressure, cardiovascular disease and survival. J Am Coll Nutr 2006; 25(3 Suppl): 247S-255S.

8 Glazier AM, Nadeau JH, Aitman TJ. Finding genes that underlie complex traits. Science 2002; 298: 2345-2349.

9 Wellcome Trust Case Control Consortium. Genome-wide association study of 14000 cases of seven common diseases and 3000 shared controls. Nature 2007; 447: 661-678.

10 Levy D, Larson MG, Benjamin EJ, Newton-Cheh C, Wang TJ, Hwang SJ, Vasan RS, Mitchell GF. Framingham heart study $100 \mathrm{~K}$ project: genome-wide associations for blood pressure and arterial stiffness. BMC Med Genet 2007; 8(Suppl 1): S3.

11 Levy D, Ehret GB, Rice K, Verwoert GC, Launer LJ, Dehghan A, Glazer NL, Morrison AC, Johnson AD, Aspelund T, Aulchenko Y, Lumley T, Kottgen A, Vasan RS, Rivadeneira F, Eiriksdottir G, Guo X, Arking DE, Mitchell GF, Mattace-Raso FU, Smith AV, Taylor K, Scharpf RB, Hwang SJ, Sijbrands EJ, Bis J, Harris TB, Ganesh SK, O'Donnell CJ, Hofman A, Rotter JI, Coresh J, Benjamin EJ, Uitterlinden AG, Heiss G, Fox CS, Witteman JC, Boerwinkle E, Wang TJ, Gudnason V, Larson MG, Chakravarti A, Psaty $\mathrm{BM}$, van Duijn CM. Genome-wide association study of blood pressure and hypertension. Nat Genet 2009; 41: 677-687.

12 Newton-Cheh C, Johnson T, Gateva V, Tobin MD, Bochud M, Coin L, Najiar SS, Zhao JH, Heath SC, Eyheramendy S, Papadakis K, Voight BF, Scott LJ, Zhang F, Farrall M, Tanaka T, Wallace C, Chambers JC, Khaw KT, Nilsson P, van der Harst P, Polidoro S, Grobbee DE, Onland-Moret NC, Bots ML, Wain LV, Elliott KS, Teumer A, Luan J, Lucas G, Kuusisto J, Burton PR, Hadley D, McArdle WL, Brown M, Dominiczak A, Newhouse SJ, Samani NJ, Webster J, Zeggini E, Beckmann JS, Bergmann S, Lim N, Song K, Vollenweider P, Waeber G, Waterworth DM, Yuan X, Groop L, Orho-Melander M, Allione A, Di Gregorio A, Guarrera S, Panico S, Ricceri F, Romanazzi V, Sacerdote C, Vineis P, Barroso I, Sandhu MS, Luben RN, Crawford GJ, Jousilahti P, Perola M, Boehnke M, Bonnycastle LL, Collins FS, Jackson AU, Mohlke KL, Stringham HM, Valle TT, Willer CJ, Bergman RN, Morken MA, Döring A, Gieger C, Illig T, Meitinger T, $\operatorname{Org}$ E, Pfeufer A, Wichmann HE, Kathiresan S, Marrugat J, O'Donnell CJ, Schwartz SM, Siscovick DS, Subirana I, Freimer NB, Hartikainen AL, McCarthy MI, O'Reilly PF, Peltonen L, Pouta A, de Jong PE, Snieder $H$, van Gilst WH, Clarke R, Goel A, Hamsten A, Peden JF, Seedorf U, Syvänen AC, Tognoni G, Lakatta EG, Sanna S, Scheet P, Schlessinger D, Scuteri A, Dörr M, Ernst F, Felix SB, Homuth G, Lorbeer R, Reffelmann T, Rettig R, Völker U, Galan P, Gut IG, Hercberg S, Lathrop GM, Zelenika D, Deloukas P, Soranzo N, Williams FM, Zhai G, Salomaa V, Laakso M, Elosua R, Forouhi NG, Völzke H, Uiterwaal CS, van der Schouw YT, Numans ME, Matullo G, Navis G, Berglund G, Bingham SA, Kooner JS, Connell JM, Bandinelli S, Ferrucci L, Watkins H, Spector TD, Tuomilehto J, Altshuler D, Strachan DP, Laan M, Meneton P, Wareham NJ, Uda M, Jarvelin MR, Mooser V, Melander O, Loos RJ, Elliott $P$, Abecasis GR, Caulfield M, Munroe PB. Genome-wide association study identifies eight loci associated with blood pressure. Nat Genet 2009; 41: 666-676.

13 Cho YS, Go MJ, Kim YJ, Heo JY, Oh JH, Ban HJ, Yoon D, Lee MH, Kim DJ, Park M, Cha SH, Kim JW, Han BG, Min H, Ahn Y, Park MS, Han HR, Jang HY, Cho EY, Lee JE, Cho NH, Shin C, Park T, Park JW, Lee JK, Cardon L, Clarke G, McCarthy MI, Lee JY, Lee JK, Oh B, Kim HL. A large-scale genome-wide association study of Asian populations uncovers genetic factors influencing eight quantitative traits. Nat Genet 2009; 41: 527-534.

14 Sanada H, Yatabe J, Midorikawa S, Hashimoto S, Watanabe T, Moore JH, Ritchie MD, Williams SM, Pezzullo JC, Sasaki M, Eisner GM, Jose PA, Felder RA. Single-nucleotide polymorphisms for diagnosis of salt-sensitive hypertension. Clin Chem 2006; 52: 352-360.
15 Dahlberg J, Nilsson LO, von Wowern F, Melander O. Polymorphism in NEDD4L is associated with increased salt sensitivity, reduced levels of $P$-renin and increased levels of Nt-proANP. PLoS One 2007; 2: e432.

16 Wang Y, O'Connell JR, McArdle PF, Wade JB, Dorff SE, Shah SJ, Shi X, Pan L, Rampersaud E, Shen H, Kim JD, Subramanya AR, Steinle NI, Parsa A, Ober CC, Welling PA, Chakravarti A, Weder AB, Cooper RS, Mitchell BD, Shuldiner AR, Chang YP. Whole-genome association study identifies STK39 as a hypertension susceptibility gene. Proc Natl Acad Sci USA 2009; 106: 226-231.

17 Staessen JA, Kuznetsova T, Zhang $H$, Maillard M, Bochud M, Hasenkamp S, Westerkamp J, Richart T, Thijs L, Li X, Brand-Herrmann SM, Burnier M, Brand E. Blood pressure and renal sodium handling in relation to genetic variation in the DRD1 promoter and GRK4. Hypertension 2008; 51: 1643-1650.

18 Stephens M, Smith NJ, Donnelly P. A new statistical method for haplotype reconstruction from population data. Am J Hum Genet 2001; 68: 978-989.

19 Barrett JC, Fry B, Maller J, Daly MJ. Haploview: analysis and visualization of LD and haplotype maps. Bioinformatics 2005; 21: 263-265.

20 Moore JH, Williams SM. New strategies for identifying gene-gene interactions in hypertension. Ann Med 2002; 34: 88-95.

21 Beeks E, Kessels AG, Kroon AA, van der Klauw MM, de Leeuw PW. Genetic predisposition to salt-sensitivity: a systematic review. J Hypertens 2004; 22: 1243-1249.

22 Katsuya T, Ishikawa K, Sugimoto K, Rakugi H, Ogihara T. Salt sensitivity of Japanese from the viewpoint of gene polymorphism. Hypertens Res 2003; 26: 521-525.

23 Gros R, Afroze T, You XM, Kabir G, Van Wert R, Kalair W, Hoque AE, Mungrue IN, Husain M. Plasma membrane calcium ATPase overexpression in arterial smooth muscle increases vasomotor responsiveness and blood pressure. Circ Res 2003; 93: 614-621.

24 Hong KW, Go MJ, Jin HS, Lim JE, Lee JY, Han BG, Hwang SY, Lee SH, Park HK, Cho YS, Oh B. Genetic variations in ATP2B1, CSK, ARSG and CSMD1 loci are related to blood pressure and/or hypertension in two Korean cohorts. J Hum Hypertens 2010; 24: 367-372.

25 Hong KW, Jin HS, Lim JE, Kim S, Go MJ, Oh B. Recapitulation of two genomewide association studies on blood pressure and essential hypertension in the Korean population. J Hum Genet 2010; 55: 336-341.

26 Eden A, Benvenisty N. Involvement of branched-chain amino acid aminotransferase (Bcat1/Eca39) in apoptosis. FEBS Lett 1999; 457: 255-261.

27 Sakamoto K, Yamasaki Y, Kaneto H, Fujitani Y, Matsuoka T, Yoshioka R, Tagawa T, Matsuhisa M, Kajimoto Y, Hori M. Identification of oxidative stress-regulated genes in rat aortic smooth muscle cells by suppression subtractive hybridization. FEBS Lett 1999; 461: 47-51.

28 Hong KW, Jin HS, Cho YS, Lee JY, Lee JE, Cho NH, Shin C, Lee SH, Park HK, Oh B. Replication of the wellcome trust genome-wide association study on essential hypertension in a Korean population. Hypertens Res 2009; 32: 570-574.

29 Korc M, Friesel RE. The role of fibroblast growth factors in tumor growth. Curr Cancer Drug Targets 2009; 9: 639-651.

30 Szebenyi G, Fallon JF. Fibroblast growth factors as multifunctional signaling factors. Int Rev Cytol 1999; 185: 45-106.

31 Caprioli J, Mele C, Mossali C, Gallizioli L, Giacchetti G, Noris M, Remuzzi G, Benigni A. Polymorphisms of EDNRB ATG, and ACE genes in salt-sensitive hypertension. Can J Physiol Pharmacol 2008; 86: 505-510.

32 Wang R, Zhong B, Liu Y, Wang C. Association between alpha-adducin gene polymorphism (Gly460Trp) and genetic predisposition to salt sensitivity: a meta-analysis. J Appl Genet 2010; 51: 87-94.

33 Lanzani C, Citterio L, Jankaricova M, Sciarrone MT, Barlassina C, Fattori S, Messaggio E, Serio CD, Zagato L, Cusi D, Hamlyn JM, Stella A, Bianchi G, Manunta P. Role of the adducin family genes in human essential hypertension. J Hypertens 2005; 23: 543-549. 